\title{
PREDICADOS ESTATIVOS E OS TIPOS DE DEÔNTICO: OUGHT-TO-DO E OUGHT-TO-BE
}

\author{
NÚBIA FERREIRA RECH ${ }^{2}$ \\ (UFSC) \\ GIUSEPPE VARASCHIN ${ }^{3}$ \\ (UFSC)
}

\begin{abstract}
RESUMO: Neste artigo, investigamos a natureza dos estativos que formam sequência com deônticos. Nosso objetivo foi avaliar o papel que as propriedades desses predicados sob o escopo do modal desempenham na sua interpretação. Apresentamos evidências do português brasileiro, reforçadas por dados do Paresi (Brandão 2014), para a postulação de estados passíveis de controle. Essa divisão da classe dos estativos, já sinalizada por Parsons (1990) e Basso e Ilari (2004), possibilitou rastrear diferenças entre dois tipos de deônticos: ought-to-do e ought-to-be, separação assumida por Brennan (1993) e Hacquard (2006). Constatamos que os primeiros funcionam apenas com estativos controláveis, enquanto os últimos funcionam com todos os tipos de estativos; manifestam, entretanto, restrição relativa à leitura do DP. Essas evidências fornecem respaldo adicional à hipótese aventada em Rech e Giachin (2014) e Pires de Oliveira e Rech (2016), segundo a qual a definição da modalidade está atrelada às propriedades do predicado sob o escopo do modal.
\end{abstract}

Palavras-chave: modalidade deôntica; predicados estativos; traço [ \pm controle].

ABSTRACT: In this article, we investigate the nature of statives that occur with deontics. Our objective was to evaluate how the properties of these predicates influence the interpretation of the modal. We present some evidence from Brazilian Portuguese, reinforced by data from Paresi, to motivate postulating controllable states. This division of the stative class - one already indicated by Parsons (1990) and Basso and Ilari (2004) - allowed us to distinguish two types of deontics: ought-todo and ought-to-be, a separation adopted by Brennan (1993) and Hacquard (2006). The first type works only with controllable states, whilst the second works with all kinds of states; albeit a restriction that has to do with the reading assumed by the DP. Such evidence grants further support to the hypothesis suggested by Rech and Giachin (2014) and Pires de Oliveira and Rech (2016), according to which the definition of modality is linked to properties of the predicate that is within the modal's scope.

Keywords: deontic modality; stative predicates; [ \pm control] feature.

\footnotetext{
${ }^{1}$ Expressamos nosso agradecimento ao $\mathrm{CNPq}$ pelo incentivo a esta pesquisa através de auxílio financeiro (Processo 424025/ 2016-7), à Ana Paula Brandão pelos dados do Paresi e à Roberta Pires de Oliveira por seus comentários e correções em uma versão preliminar. Agradecemos também aos dois pareceristas anônimos da Caderno de Estudos Linguísticos, cujos comentários e sugestões contribuíram significativamente para a qualificação do artigo.

${ }^{2}$ Universidade Federal de Santa Catarina, Florianópolis (SC), Brasil. nubia.rech@ufsc.br

${ }^{3}$ Universidade Federal de Santa Catarina, Florianópolis (SC), Brasil. giuseppe.varaschin@gmail.com
} 


\section{INTRODUÇ̃̃OO}

Neste artigo, nos propomos a investigar a natureza dos predicados estativos que formam sequência com os modais deônticos no português brasileiro (PB). $\mathrm{O}$ objetivo do nosso estudo foi avaliar o papel que as propriedades desses predicados sob o escopo do modal desempenham na sua interpretação. $\mathrm{O}$ tipo de dado que motivou o estudo foi o que revela contrastes como os de (1a-c) abaixo:

(1) a. Helena deve estar doente.

b. Sara deve ser corajosa no tribunal.

c. A filha da protagonista deve ser bilíngue.

Nas três sentenças, há um predicado estativo sob o escopo de um mesmo auxiliar modal (dever); é importante notar, entretanto, que as interpretações disponíveis aos operadores de modalidade são distintas em cada caso. Em (1a), o modal é interpretado como um epistêmico. Em (1b), uma das interpretações possíveis é a deôntica, em que se atribui à Sara uma obrigação de realizar ações que resultem em uma conduta corajosa no tribunal. Já em (1c), além de leitura epistêmica, é possível também uma leitura deôntica, mas de outro tipo, em que se dá uma ordem para que o ouvinte garanta que a filha da protagonista seja bilíngue. Note que não é possível interpretar (1a) como deôntico nem (1c) como um deôntico do mesmo tipo que o deôntico que figura em (1b).

A fim de esclarecer fatos como esses, nossa análise considerou também alguns dados do Paresi, uma língua da família Aruák, falada no Estado do Mato Grosso, por essa língua exibir um sistema de alinhamento semântico, no qual é marcada uma distinção entre estativos ativos e passivos.

Em línguas nominativas, como o português, o traço semântico que determina a relação entre o predicado e seu(s) argumento(s) pode não ser tão evidente no caso dos predicados estativos, dado que eles parecem não formar uma classe homogênea. Assumimos, contudo, a abordagem de que, mesmo nessas línguas, há evidências da existência de dois tipos de predicados estativos: aqueles que podem e aqueles que não podem ser controlados (cf.: BACH 1981; PARSONS 1990; BERTINETTO 1991; BASSO \& ILARI 2004) - em contraposição a abordagens mais tradicionais, como a de Vendler (1967). Nossa hipótese é que essa cisão interna à classe dos estativos tem implicações para a interpretação de um deôntico que encabeçasse essas eventualidades. Trata-se, nesse sentido, de uma extensão das conclusões do estudo experimental de Pires de Oliveira e Rech (2016), cujos dados revelaram que os falantes do PB são sensíveis à presença de um agente no predicado encaixado quando atribuem interpretações deônticas. Aqui, todavia, o foco de análise não é o contraste entre inergativos e inacusativos, mas sim entre diferentes tipos de estativos. Essa diferença foi relevante para motivar um olhar mais detalhado ao tipo de eventualidade sob escopo do modal. 
Este artigo está organizado de forma a, na seção 1, apresentar nossa proposta para explicar as diferentes interpretações deônticas em construções com predicados estativos. Na seção 2, fornecemos alguns argumentos que apontam para a necessidade de postularmos estados passíveis de controle (negando, assim, a total homogeneidade da classe dos estativos) e esboçamos algumas considerações sobre as características semânticas desses predicados. Por fim, na seção 3, abordamos a relação entre estativos - passíveis de controle e não passíveis de controle - e a modalidade deôntica, sob a perspectiva da existência de dois tipos de deônticos: ought-to-do e ought-to-be (cf.: FELDMAN 1986; BRENNAN 1993; HACQUARD 2006; PIRES DE OLIVEIRA \& RECH 2016).

\section{PROPOSTA}

O objetivo principal deste artigo é avaliar a hipótese de Pires de Oliveira e Rech (2016) em construções estativas. Em linhas gerais, as autoras propõem que deônticos precisam checar o traço agentivo [+Ag] contra um dos participantes do evento ao qual se relativizam. Conforme Brennan (1993), um modal deôntico pode ser interpretado em posição baixa, onde acessa o evento denotado pelo VP e seus participantes; ou em posição alta, onde acessa o ato de fala. Essa diferença na altura de interpretação do deôntico deu sustentação à proposta de separação desses modais em dois tipos: deônticos ought-to-do e ought-to-be. Os primeiros são orientados para o sujeito da sentença; já os últimos, para um participante do evento de fala, normalmente o addressee (cf.: HACQUARD 2006).

Neste artigo, vamos avançar na hipótese - apresentada por Rech e Giachin (2014) em versão preliminar - de que a interpretação do auxiliar modal deôntico é determinada em parte pela sintaxe, pois depende das propriedades do predicado lexical. Como já se insinuou em (1), parece haver uma diferença em relação ao tipo de interpretação disponível para o modal em construções com estativos como ser alto em comparação àquelas com estativos como ser cauteloso: "Pedro deve ser alto" vs "Pedro deve ser cauteloso". Na primeira sentença, independentemente do contexto de emprego, o modal deve será associado apenas à interpretação epistêmica; já na segunda sentença, além da epistêmica, este modal admite interpretação deôntica, podendo ser empregado em contextos nos quais a obrigação de agir com cautela em determinada situação recai sobre Pedro. Neste artigo, vamos argumentar que essa diferença está atrelada ao perfil inferencial de cada tipo de estativo, em particular, a relações de acarretamento, que não determinam um predicado como ser alto, mas determinam um predicado como ser cauteloso. Estados como ser cauteloso, ser corajoso e morar em Paris apresentam fases preparatórias executáveis pelo próprio participante da eventualidade descrita pelo estado; essa estrutura de evento é que torna disponível a leitura deôntica do tipo ought-to-do, em que a obrigação ou permissão recai sobre o sujeito da sentença. 
Ressaltamos que nossa proposta para explicar as diferentes interpretações deônticas - ought-to-do e ought-to-be - em construções com predicados estativos considera que estativos como ser cauteloso, ser corajoso, estar quieto, morar em Paris são passíveis de controle; enquanto estativos como ser alto, ser bilíngue, ter olhos azuis, estar doente, não. Nossa argumentação é que o deôntico ought-to-do exige um participante agentivo em posição baixa; este deve, portanto, estar acessível na eventualidade descrita em VP. ${ }^{4}$ Já o deôntico ought-to-be não impõe essa restrição, por isso forma sequência com quaisquer predicados estativos - aspecto que será abordado na seção 3.2. A posição de checagem do traço [+Ag] tem reflexos na orientação do modal, permitindo identificar se se trata de um deôntico do tipo ought-to-do ou ought-to-be.

\section{O TRAÇO [ \pm AG] EM PREDICADOS ESTATIVOS}

Afirmamos, na apresentação da nossa proposta, que os predicados estativos que podem formar sequência com um modal deôntico do tipo ought-to-do são precisamente aqueles que podem ser controlados por um participante com propriedades agentivas. Independentemente do estudo dos operadores modais, a observação de que há estados passíveis de algum tipo de controle por parte de um agente já está amplamente difundida na literatura sobre aspecto inerente (cf.: PARSONS 1990; YANG 1997; BERTINETTO 1991; BASSO \& ILARI 2004). Os autores que defendem essa posição argumentam que a distinção entre predicados dinâmicos e estativos independe da distinção entre predicados passíveis de controle e não passíveis de controle. Diante dessas constatações, é esperado que encontremos, além de predicados dinâmicos não passíveis de controle - p. ex., inacusativos como morrer e cair, que também não formam sequência com deônticos do tipo ought-to-do (cf.: PIRES DE OLIVEIRA \& RECH 2016) -, casos de estados controláveis.

\footnotetext{
${ }^{4}$ Nossa proposta para explicar a presença de um participante agentivo no VP correspondente a predicados estativos é a de que estativos passíveis de controle podem denotar eventualidades com estruturas enriquecidas, à semelhança do que Rothstein (2004) propõe para os achievements que se combinam com o aspecto progressivo. Estamos supondo que estados controláveis - que também aceitam a perífrase progressiva - apresentam etapas anteriores à eventualidade que descrevem. Logo, projetam uma eventualidade com estrutura enriquecida, em cujas fases preparatórias há um participante agentivo. Este faria parte, portanto, da estrutura incrementada do VP e, assim, estaria acessível ao deôntico ought-to-do, possibilitando a checagem do traço [+Ag] em posição baixa. $\mathrm{O}$ agente das fases preparatórias, que podem ser concebidas como integrantes da eventualidade, corresponde ao argumento do estativo, que se realiza como sujeito da sentença. Por isso, a interpretação ought-to-do - em que a orientação do modal recai, geralmente, sobre o sujeito - está disponível em construções com estativos passíveis de controle. Não é nosso objetivo neste artigo aprofundar este ponto, que será detalhado em produção futura.
} 
Os autores que sublinham a existência de tais estados (e a consequente heterogeneidade da classe aspectual dos estativos) fundamentam essa posição teórica submetendo predicados tradicionalmente tidos como estados a testes de agentividade (KENNY 1963; DOWTY 1979), tais quais: (1) a possibilidade de aparecer em contextos encaixados com verbos como forçar, obrigar e tentar; (2) a admissibilidade no imperativo; (3) a coocorrência com advérbios agentivos como deliberadamente, voluntariamente e cuidadosamente; e (4) a aceitabilidade em construções pseudoclivadas do tipo $O$ que A fez foi X. Inserir um predicado em contextos linguísticos que demandam traço agentivo do sujeito configura um parâmetro mais objetivo, para além da simples intuição semântica, para aferir quando temos, de fato, um estado passível de controle.

Podemos dizer, sem nenhuma anomalia, que Pedro tentou (ou foi obrigado a) morar em Paris, que Maria foi deliberadamente cautelosa e que o que Márcio fez foi ser prudente. Podemos, igualmente, falar, no imperativo, João, fique quieto!. Esses testes falham, entretanto, com estativos como ser alto, ser daltônico, ter olhos azuis e estar doente. Tais testes revelam que apenas os primeiros estativos envolvem alguma noção de controle por parte do sujeito, e são justamente estes que, em construções com auxiliares modais, possibilitam uma leitura deôntica do tipo ought-to-do-em que a obrigação ou permissão recai sobre o sujeito da sentença. Os resultados desses testes dão suporte adicional à proposta de Pires de Oliveira e Rech (2016), segundo a qual os modais deônticos ought-to-do precisam checar o traço agentividade $[+\mathrm{Ag}]$ com um participante do evento descrito pelo VP.

Além de passarem nos habituais testes de agentividade, há outras propriedades comuns aos estados controláveis que podem nos ajudar a identificá-los. Uma delas é o seu peculiar perfil inferencial. Uma diferença básica entre estados não passíveis de controle (como ser alto, ter olhos azuis, estar doente, falar português e saber matemática) e os passíveis de controle (ser prudente, estar quieto, ser cauteloso e morar em Paris) é que estes, ao contrário daqueles, parecem tanto acarretar quanto serem acarretados por eventos praticáveis por um participante correferencial ao argumento do estado. 
Podemos entender que um estado como ser prudente está inferencialmente atrelado a uma série de eventos que devem ser praticados pelo próprio sujeito a quem a propriedade prudente será atribuída. Por exemplo: se Márcio foi prudente na reunião, poderíamos inferir que ele não interrompeu seus superiores, que ele apresentou propostas razoáveis, que ele não fez nenhum comentário agressivo, etc. Igualmente, se ele realizou essas ações nesse contexto, podemos concluir que ele foi prudente. Faria sentido que alguém perguntasse como eu posso ser prudente? e recebesse, em resposta, um conjunto de ações ou eventos que deve praticar. ${ }^{5}$ Vale dizer que o conjunto exato dos eventos que acarretam o estado ser prudente não pode ser determinado fora de contexto, devido à própria vagueza do predicado em questão. Propostas como a de Recanati (2010) e Sperber e Wilson (2012) sugerem que o conteúdo lexical de uma expressão como prudente precisa ser enriquecido (ou pelo contexto extralinguístico, ou por um PP locativo explicitamente enunciado). A depender do modo como o sentido do predicado é especificado, a expressão ser prudente poderia se referir a propriedades distintas, como ser prudente no trânsito, ser prudente em reuniões de negócios e ser prudente durante uma cirurgia, cada uma das quais é acarretada por (e acarreta) um conjunto distinto de eventos; por isso a impossibilidade de especificar, em abstrato, o conjunto exato de eventos que esse predicado abarca.

Um exemplo que aponta fortemente o caráter dedutivo (e, portanto, segundo certa concepção, semântico) dessas inferências é o de morar em Paris. Seria estranho imaginar a seguinte ordem:

(2) ? João, more em Paris! Mas não vá até lá, não compre nem alugue um imóvel, não durma lá durante nenhuma noite do ano, não se alimente lá. Na verdade, não pise sequer seus pés em Paris.

Parece que estamos diante de uma ordem contraditória, porque o estado morar em Paris acarreta que João deve realizar certos eventos como comprar ou alugar um imóvel e dormir e fazer refeições na cidade (e, do mesmo modo, esses eventos acarretam o predicado em questão). Igualmente, (3) seria uma asserção semanticamente anômala (possivelmente autocontraditória):

\footnotetext{
${ }^{5}$ Talvez seja essa uma motivação subjacente às análises de Partee (1977) e Parsons (1990), que postulam uma ambiguidade inerente à cópula "be" do inglês. Segundo esses autores, além de um sentido estativo clássico de atribuição de propriedade, a cópula apresentaria um sentido agentivo - chamado ACT BE. Ser prudente seria, nesses casos, simplesmente o mesmo que agir prudentemente. Nosso enquadramento da discussão apresenta - para os nossos propósitos ao menos - algumas vantagens em relação a esse. Ao falarmos, genericamente, de estados e não especificamente de uma cópula agentiva, abarcamos casos de estados que não se expressam linguisticamente com a cópula, mas que se comportam de modo semelhante (tanto em relação aos testes quanto em relação ao perfil inferencial), tais como morar em Madrid, usar chinelos, permanecer em Londres, portar uma arma ou assemelhar-se ao David Bowie. Não nos comprometemos, tampouco, com nenhuma postulação de ambiguidade inerente aos itens lexicais "ser" e "estar". Essa proliferação de significados lexicais pode ser metodologicamente inconveniente, principalmente quando ela é utilizada para explicar o comportamento de expressões equivalentes em várias línguas.
} 
(3) ? João passa todos os dias do ano em Paris, tem residência fixa, faz suas refeições e dorme todas as noites lá, mas ele não mora em Paris.

A contradição é precisamente o efeito que se produz quando afirmamos uma proposição e negamos seus acarretamentos. Não parece haver nenhum mundo em que João faça todas essas coisas e não more em Paris, ou um mundo em que João more em Paris, mas não faça nenhuma dessas coisas. Teríamos, portanto, aparentemente, uma relação de equivalência tautológica (duplo acarretamento) entre o estado passível de controle e um conjunto mais ou menos vago - possivelmente um cluster, no sentido de Searle (1958) - de eventos praticados por um participante correferencial ao sujeito do estado. No caso específico de morar, esse conjunto de eventos é menos variável contextualmente do que o de ser prudente. ${ }^{6}$

O mesmo comportamento não é observado com estados não passíveis de controle. Não há nenhum conjunto de eventos (que o sujeito seja capaz de realizar) que deva ser satisfeito para que esses predicados se apliquem. Em outras palavras, uma pessoa não precisa (e nem conseguiria) fazer algo para ser alta ou daltônica. Mesmo um predicado stage-level, como estar doente, pode ser, no máximo, provável na realização de um conjunto de eventos. A conexão aí é de probabilidade, e não de acarretamento. Não é contraditório dizer:

(4) João dormiu mal, não se agasalhou, saiu de cabelos molhados pela rua, cumprimentou pessoas gripadas, e não ficou doente.

Nem, tampouco:

(5) João ficou doente, apesar de ter se agasalhado, dormido bem, secado os cabelos e evitado o contato com pessoas gripadas.

Isso porque o predicado estar doente não é acarretado por um conjunto de ações praticadas por João. Esse estado é meramente provável dadas essas atitudes. Não há nada que João possa fazer para assegurar que ele vá (ou não vá) ficar doente. Se ficamos sabendo que João está doente, não podemos garantir que ele tenha feito qualquer coisa em particular que resultou neste estado, diferentemente do que sucede com estados controláveis, como ser prudente (em uma reunião) e morar em Paris.

Os sujeitos dos estativos passíveis de controle precisam ser capazes de realizar uma série de eventos contextualmente salientes, que estão, segundo nossa análise, tautologicamente vinculados ao estado. Os estados controláveis, são, portanto, eventualidades enriquecidas, que contêm, como partes, subeventos preparatórios que são executados pelo sujeito a quem a propriedade do estado é atribuída. Em outras palavras: cada estado controlável está tautologicamente associado a um cluster de eventos contextualmente salientes, que devem poder ser realizados pelo próprio sujeito do predicado estativo. Logo, deve haver um participante agentivo na eventualidade descrita pelo VP.

${ }^{6}$ Essa análise requer refinamento, e o caráter do nexo inferencial (equivalência, acarretamento unidirecional ou uma simples inferência pragmática forte) precisa ser melhor investigado. 
Uma evidência ainda mais forte, diríamos até determinante, para inferir um traço $[+\mathrm{Ag}]$ na eventualidade descrita por alguns estados - aqueles capazes de denotar tipos de eventualidades com estrutura enriquecida - vem do estudo de línguas tipologicamente diversas. Algumas línguas que exibem o sistema de alinhamento semântico - termo proposto por Donohue e Wichmann (2008) - dispõem de marcas morfológicas que sinalizam os papéis temáticos de agente e paciente. $\mathrm{O}$ Paresi, que foi estudado por Brandão (2014), exibe uma marcação desse tipo em pronomes proclíticos, que se dividem em dois grupos. A tabela a seguir apresenta os marcadores pronominais dos grupos $\mathrm{A}$ e $\mathrm{B}$, cada um dos quais relacionado à retomada de um tipo de argumento:

Tabela 1: Grupos dos proclíticos em Paresi (BRANDÃO, 2014: 81).

\begin{tabular}{|l|l|l|}
\hline & Grupo A & Grupo B \\
\hline $1 \mathrm{sg}$ & $\underline{\mathrm{na}}=$ & $\underline{\mathrm{no}}=$ \\
\hline $2 \mathrm{sg}$ & $\underline{\mathrm{ha}}=$ & $\underline{\mathrm{hi}}=$ \\
\hline $3 \mathrm{sg}$ & $\varnothing=$ & $\varnothing=$ \\
\hline $1 \mathrm{pl}$ & $\underline{\mathrm{wa}}=$ & $\underline{\mathrm{wi}}=$ \\
\hline $2 \mathrm{pl}$ & $\underline{\mathrm{za}}=$ & $\underline{\mathrm{xI}}=$ \\
\hline $3 \mathrm{pl}$ & $\varnothing=\ldots$-ha & $\varnothing=\ldots$-ha \\
\hline
\end{tabular}

Os pronomes do Grupo A são empregados para retomar argumentos ativos; já os pronomes do Grupo B retomam argumentos tematicamente marcados como pacientes. O exemplo (6), a seguir, ilustra essa marcação:

(6) a. na=tona

$1 \mathrm{~s}=$ caminhar

'Eu caminhei.'

b. na=zawatya haira

$1 \mathrm{~s}=$ jogar bola

'Eu joguei a bola.'

c. no=waini-hena

$1 \mathrm{~s}=$ morrer-TRS

'Eu vou morrer.'

Sintaticamente, alguns verbos intransitivos, como tona (caminhar), recebem a mesma marcação de sujeito que os verbos transitivos (os proclíticos do Grupo A), conforme mostram as sentenças em (6a) e (6b); enquanto outros verbos intransitivos, como waini (morrer), recebem uma marcação de sujeito diferente (os proclíticos do grupo B), conforme (6c).

O contraste de gramaticalidade entre (7a-b) e (8a-b) indica que uma mesma raiz lexical não pode se combinar com proclíticos pertencentes a diferentes grupos: 
(7) a. na=tema

$1 \mathrm{~s}=$ correr

'Eu corri.'

b. *no=tema

(8) a. no=nak-ita

$1 \mathrm{~s}=$ estar.com.fome-IFV

'Eu estou com fome.'

b. *na=nak-ita

Note que o verbo tema (correr) se combina com o proclítico $n a=$, pertencente ao Grupo A. Este verbo não pode figurar com marcadores do Grupo B, conforme a má-formação de $(7 \mathrm{~b})$, em que tema aparece com o proclítico $n o=$. O estativo naka (estar com fome), por sua vez, se combina com um proclítico do Grupo B $(n o=)$, conforme $(8 \mathrm{a})$, rejeitando proclíticos do Grupo A, como se depreende da má-formação de $(8 b)$.

O interessante para nossos propósitos é observar que nem todos os estativos se combinam com proclíticos do Grupo B, que retomam um argumento passivo. Compare os exemplos (9) e (10) a seguir:

(9) a. na=waiye-ze-heko-la $1 \mathrm{~s}=$ ser.bom-NMLZ-pensar-?

'Eu sou prudente' (lit.: 'Eu sou uma pessoa que pensa bem')

b. na=waiye-ze-hare

1s=ser.bom-NMLZ-M

'Eu sou uma pessoa legal'

(10) a. no=wahahare

$1 \mathrm{~s}=$ ser.alto

'Eu sou alto'

b. no=waxirahare

$1 \mathrm{~s}=$ ser.feio

'Eu sou feio'

Os exemplos (9) e (10) revelam que a distribuição de caso gramatical em Paresi não pode ser explicada por uma oposição entre a classe dos estativos e as demais classes aspectuais, em que a primeira, por ser marcada com o traço [-dinâmico], não figuraria com pronomes com caso correspondente a argumentos ativos; e as demais, por serem marcadas com o traço [+dinâmico], figurariam com pronomes com caso ativo na função de sujeito. A ocorrência de predicados estativos com pronomes flexionados tanto no caso associado a argumentos ativos, conforme os exemplos em (9a) e (9b), quanto no caso associado a argumentos passivos, conforme os exemplos em (10a) e (10b), indica que os estativos não correspondem a uma classe homogênea, podendo diferir quanto à presença de um traço $[+\mathrm{Ag}]$ no participante da eventualidade que descrevem, no caso de a eventualidade apresentar fases preparatórias. 
Na próxima seção, vamos mostrar que os predicados estativos que passam nos testes de agentividade citados aqui e que são determinados por relações de acarretamento (ser prudente, ser cauteloso, morar em Paris, estar quieto) - os quais correspondem àqueles que figuram com proclíticos do Grupo A no Paresi-licenciam uma interpretação do tipo ought-to-do para o deôntico. Já aqueles que não passam nos testes de agentividade nem são determinados por relações de acarretamento (ser alto, ser daltônico, ter olhos azuis, estar doente) - os que figuram com proclíticos do Grupo B no Paresi - são compatíveis apenas com a interpretação deôntica do tipo ought-to-be. Isso é um reforço à nossa hipótese, segundo a qual a interpretação ought-to-do depende da presença de um participante [+Ag] na eventualidade descrita pelo predicado estativo sob o escopo do modal.

\section{PREDICADOS ESTATIVOS E O TIPO DE DEÔNTICO}

A identificação de dois tipos de deônticos - ought-to-be e ought-to-do - teve por base evidências advindas de estudos de interface entre a semântica e a sintaxe na análise dos auxiliares modais. A observação de que haveria uma distinção conceitual entre diferentes tipos de obrigação - uma que recai sobre um indivíduo específico (ought-to-do) e outra que configura uma norma abstrata a respeito de como certas coisas devem ser (ought-to-be) - foi feita originalmente por Feldman (1986) e aplicada à sintaxe por Brennan (1993).

Neste trabalho, assumimos uma proposta mais recente, de autoria de Hacquard (2006, 2010), que insere essa discussão em um debate teórico e empiricamente rico a respeito da interface entre a sintaxe e a semântica dos modais. Hacquard busca, grosso modo, conciliar a proposta de Kratzer (1981, 2001, 2012) com a de Cinque $(1999,2006)$, mantendo a postulação de um único item lexical, mas reconhecendo suas diferenças em relação às categorias de tempo e aspecto.

A proposta semântica representada por Kratzer (1981, 2001, 2012) assume que um mesmo modal pode ter muitas matizes, e que a diferença entre seus significados pode variar na força (existencial ou universal), na base modal (epistêmica ou circunstancial) e na fonte de ordenação (deôntica, bulética, teleológica...). A primeira seria dada lexicalmente, enquanto estas últimas seriam dadas contextualmente. A abordagem sintática representada por Cinque (1999, 2006) prevê, para cada interpretação modal, uma posição diferente na estrutura: ModEpistêmico, ModVolição, ModObrigação, ModPermissão, ModHabilidade. Neste caso, o poder epistêmico é um item distinto tanto do poder deôntico quanto do poder de capacidade, o que reflete na posição que ocupam na estrutura. Embora este autor não afirme que se tratam de itens lexicais distintos, supomos que a postulação de uma posição fixa na hierarquia para cada tipo de modal, que está rigidamente ordenado em relação a outros núcleos, deve estar pautada em alguma distinção advinda do léxico. 
Para Hacquard, a interpretação que cada item de modalidade recebe é um corolário do evento que o mesmo acessa na estrutura sintática da sentença. Há, portanto, uma parte semântica para a sua análise - a consideração das propriedades denotacionais do evento ao qual o modal se relativiza -, mas também uma parte sintática: o fato de que há apenas dois eventos (o evento de fala e o evento do VP), e que cada um deles é acessível em apenas uma posição na estrutura. A distinção entre deônticos ought-to-be e ought-to-do é reinterpretada por ela nesses termos: os deônticos ought-to-be acessariam o evento de fala, e, portanto, ocupariam posição alta na sentença, ao passo que os deônticos ought-to-do acessariam o evento VP, ocupando posição baixa.

Os exemplos a seguir, transcritos de Hacquard (2006: 40), ilustram a diferença entre esses deônticos:

(11) a. Murderers ought to go to jail.

'Assassinos devem ir para a prisão'

b. Wickham ought to apologize.

'Wichham deve desculpar-se'

Kitty has to brush her teeth.

'Kitty tem que escovar seus dentes'

A interpretação preferencial para (11a) é aquela em que 'de acordo com as leis, é o caso de assassinos irem para a prisão', não recaindo tal obrigação sobre os assassinos, e sim sobre aqueles que têm o dever de fazer com que as leis sejam cumpridas. Já em (11b), a interpretação preferencial é aquela orientada para o sujeito da sentença (Wickham), sobre o qual recai o dever de desculpar-se. Temos aí uma interpretação de deôntico baixo (ought-to-do), em que a obrigação recai sobre o próprio sujeito da sentença. Na sentença em (12), além dessa leitura com escopo baixo, o modal pode ser interpretado como um deôntico alto (ought-to-be), em que a obrigação recai sobre o addressee - que pode ser a pessoa responsável por cuidar de Kitty, garantindo que ela escove os dentes. Nas propostas de Brennan (1993) e de Hacquard (2006), o indivíduo sobre o qual recai a orientação do modal dá indícios da posição (altura) em que este foi concatenado, uma vez que corresponde a um participante do evento (alto ou baixo) que o modal acessa.

Hacquard observa, ainda, que apenas os deônticos do tipo ought-to-be se associam a um ato de fala performativo, em que o enunciado corresponde a uma ordem (ou permissão) endereçada diretamente ao addressee. Deônticos do tipo ought-to-do, por sua vez, apenas descrevem uma obrigação (ou permissão) que recai geralmente sobre o sujeito da sentença - correspondendo a asserções, não assumindo, portanto, um caráter performativo. Ressaltamos que a interpretação deôntica do tipo ought-to-do não recai, necessariamente, sobre o sujeito da sentença, como em (11b). De acordo com nossa proposta, o requisito para licenciar essa interpretação ao deôntico é que haja, no evento descrito pelo VP, um participante agentivo que possa checar o traço $[+\mathrm{Ag}]$ do deôntico. Esse participante, normalmente, corresponde ao argumento externo, que se realiza como sujeito da sentença, mas pode também figurar como adjunto, em construções passivas por exemplo: 
(13) O cão deve ser alimentado pelos donos.

Além da interpretação epistêmica, o modal deve, em (13), pode receber interpretação deôntica dos dois tipos: ought-to-do e ought-to-be. Esse exemplo indica que a interpretação deôntica ought-to-do requer um participante agentivo no evento descrito pelo VP, mas não exige que este participante corresponda ao sujeito da sentença. Neste caso, o constituinte agentivo (os donos) exerce a função de adjunto, e é com este participante que o modal faz a checagem do traço $[+\mathrm{Ag}]$, recaindo sobre os donos a obrigação de realizar o evento descrito pelo VP.

\subsection{Estativos e a interpretação deôntica ought-to-do}

De acordo com Pires de Oliveira e Rech (2016), todos os deônticos apresentam um traço [+Ag] que precisa ser satisfeito por um constituinte compatível, isto é, que porte o mesmo traço e que esteja sob o escopo do modal. Segundo as autoras, se no evento descrito pelo VP houver um participante com o traço $[+\mathrm{Ag}]$, o deôntico poderá ser checado em posição baixa; caso contrário, será interpretado em posição alta, checando seu traço contra um participante do evento de fala. Tal pesquisa, de caráter experimental, considerou o modal deôntico deve formando sequência com predicados inergativos, transitivos e inacusativos. A conclusão das autoras foi na direção de que a interpretação ought-to-do só está disponível para deve quando há no evento descrito pelo VP um participante com o traço agentivo.

Neste artigo, estamos investigando uma proposta equivalente em contextos nos quais o modal deôntico forma sequência com predicados estativos. Nesta análise, estamos considerando os estativos como predicados que não configuram uma classe homogênea em relação às propriedades do argumento que selecionam, uma vez que há predicados estativos passíveis de controle (ser prudente, ser cauteloso, estar quieto) e estativos não passíveis de controle (ser alto, ter olhos azuis, estar doente), conforme argumentamos na seção 2. É esperado que apenas os primeiros licenciem a interpretação ought-to-do, uma vez que o tipo de eventualidade que descrevem requer um participante agentivo que poderá checar o traço do deôntico. Esta análise se insere, pois, em um debate mais amplo enunciado por Pires de Oliveira e Rech (2016), segundo o qual a interpretação do modal é dependente de um elemento agentivo no evento descrito pelo VP. Se for possível constatar que deônticos ought-to-do são compatíveis somente com contextos sintáticos em que há um participante agentivo no evento descrito pelo VP, então teremos indícios de que a sintaxe determina - pelo menos em parte - a interpretação do modal. ${ }^{7}$

\footnotetext{
${ }^{7}$ No experimento realizado por Pessotto (2015), a variável complemento mostrou-se significante para a predicação da força modal. Os predicados testados pela autora foram (i) escrever a tese; (ii) estudar; (iii) sair e (iv) ser a vítima. Destes, o predicado ser a vítima apresentou resultados interessantes para o índice de Até $50 \%$, associado à modalidade fraca: para o modal poder, o percentual para esta faixa foi de $89.4 \%$; para dever, foi de $52.2 \%$; e para ter que, modal que indica necessidade, sendo raramente empregado em contextos evidenciais, o percentual foi ainda menor, de apenas 29.2\% (PESSOTTO 2015: 266-267).
} 
Para averiguar essa hipótese, discutiremos, nesta subseção, alguns contextos em que os auxiliares modais figuram com predicados estativos dos dois tipos: passíveis de controle e não passíveis de controle. Observe que a interpretação ought-to-do está disponível para o modal em (14a), mas não em (14b): ${ }^{8}$

(14) a. Pedro deve morar em Florianópolis.

b. Pedro deve ser alto.

O predicado estativo morar em Florianópolis, em (14a), é passível de controle. Nessa construção, deve pode ser interpretado como um deôntico oughtto-do, em que a obrigação de morar em Florianópolis recai sobre o próprio Pedro, que é o sujeito da sentença. Neste caso, Pedro terá de realizar alguns eventos preparatórios - deslocar-se até a cidade de Florianópolis, alugar/comprar um imóvel na cidade, etc. - que acarretem o estado morar em Florianópolis. Já em (14b), o estativo - ser alto - corresponde a um predicado não passível de controle. Como não há eventos que Pedro possa realizar que garantam o estado descrito em (14b) (ver seção 2), não podemos considerar que há um participante agentivo que atua em fases preparatórias da eventualidade descrita pelo VP. Por isso, a interpretação deôntica ought-to-do - em que a obrigação recai sobre o sujeito - não está disponível nessa sentença. Esse predicado também resulta anômalo quando submetido aos outros testes citados na seção 2 (aceitabilidade no imperativo, ocorrência em contextos encaixados com verbos como forçar e obrigar, etc.), dado que ele descreve uma propriedade não monitorável.

Em (15a-b), o argumento dos predicados estativos é um DP referencial, à semelhança das sentenças do exemplo (14); contudo, diferentemente destas, esses DPs correspondem a nomes comuns. Note que essa diferença na expressão do DP sujeito não interfere na restrição que um predicado estativo não passível de controle parece impor à interpretação deôntica ought-to-do:

(15) a. Os jornalistas podem ser inconvenientes/inoportunos. ${ }^{9}$

b. Os jornalistas podem estar doentes/febris.

${ }^{8} \mathrm{O}$ modal "deve" pode receber interpretação epistêmica tanto em (14a) quanto em (14b). Conforme Cinque (1999, 2006) e Hacquard (2006, 2010), o epistêmico corresponde a um modal alto na estrutura, localizando-se acima das categorias de tempo e de aspecto e sendo orientado para um participante do evento de fala (o próprio falante); por essa razão, não é esperado que o epistêmico sofra qualquer influência das propriedades do predicado lexical no evento descrito pelo VP. Não trataremos essa questão aqui, visto que nosso foco no artigo é o estudo dos tipos de deônticos.

${ }^{9} \mathrm{O}$ verbo "poder", além de expressar modalidade epistêmica, corresponde também a um modal deôntico de permissão no PB. Compartilha, pois, com o "ter que", na terminologia de Kratzer (2012), a base modal circunstancial, mas varia em relação à força que lexicaliza ("ter que" é um quantificador universal, e "poder" é existencial). 
Em (15a), o modal está sendo empregado com estativos que descrevem uma eventualidade com fases preparatórias em que atua um participante agentivo - Os jornalistas, o qual pode checar o traço $[+\mathrm{Ag}]$ do deôntico em posição baixa; consequentemente, a interpretação ought-to-do é disponibilizada para o modal, e a permissão que este expressa recai sobre o sujeito da sentença. Em (15b), o modal figura com estativos não passíveis de controle; não há, portanto, no evento descrito pelo VP, um participante agentivo contra o qual o deôntico possa checar seu traço. Logo, a interpretação ought-to-do não é licenciada para o deôntico. Parece mesmo muito estranho dar permissão para que alguém esteja doente ou febril, visto que estes estados não são passíveis de controle.

Em (16), apresentamos construções com o modal ter que formando sequência com um DP que pode ter leitura não referencial, isto é, um DP correspondente a uma descrição atributiva. Também nestes casos observamos a mesma restrição à interpretação deôntica ought-to-do.

(16) a. O candidato ao programa de intercâmbio tem que ser responsável.

b. O candidato ao programa de intercâmbio tem que ser de origem germânica.

À semelhança dos exemplos anteriores, em (16) a interpretação deôntica do tipo ought-to-do está disponível para o auxiliar modal ter que apenas quando forma sequência com um estativo passível de controle, o que ocorre em (16a). Neste caso, a obrigação de ser responsável recai sobre o sujeito da sentença: o candidato ao programa de intercâmbio, que tem controle sobre o estado ser responsável à medida que é capaz de realizar um cluster de eventos - tais como providenciar os documentos para a viagem, preencher os formulários, fazer os relatórios, frequentar as aulas, estudar, entregar as atividades nas datas estabelecidas, etc.-, que acarretam (e são acarretados por) este estado (ser responsável). Já em (16b), temos um predicado estativo não passível de controle (ser de origem germânica); por essa razão, a interpretação ought-to-do não está disponível para o modal. Cabe, entretanto, observar o fato curioso de que, diferentemente dos exemplos (14b) e (15b), em que nenhuma interpretação deôntica é licenciada para predicados estativos não passíveis de controle, em (16b) - em que o DP sujeito corresponde a uma descrição atributiva - o modal ter que pode ter leitura deôntica, desde que a obrigação não recaia sobre o sujeito da sentença. Trata-se, portanto, do deôntico do tipo ought-to-be, do qual trataremos na próxima subseção.

\subsection{Estativos e a interpretação deôntica ought-to-be}

Em qualquer situação normal de fala, haverá sempre um ouvinte que poderá checar o traço $[+\mathrm{Ag}$ ] do deôntico. Isso presumivelmente significa que, mesmo na ausência de um argumento agentivo no evento descrito pelo VP, haverá um agente (o addressee) no evento de fala, sobre o qual poderá recair a orientação deste modal. Nesses casos, temos a instância de um deôntico alto (ought-to-be). Tal raciocínio nos levaria a crer que sobre esse tipo de interpretação deôntica não pesa nenhuma restrição, diferentemente da interpretação do tipo ought-to-do. Se a checagem do traço [+Ag] fosse condição necessária e suficiente para licenciar uma 
leitura deôntica, a interpretação do tipo ought-to-be deveria sempre estar disponível para o modal, visto que em toda situação de fala temos um agente em potencial (o addressee). Isso, contudo, não se verifica, como veremos na sequência.

De fato, para todos os casos de predicados estativos em que constatamos a possibilidade da leitura ought-to-do-i.e., os estativos passíveis de controle-podemos observar que há também a disponibilidade da leitura ought-to-be:

(17) O jornalista/João deve residir em São Paulo.

(18) O candidato ao programa de intercâmbio tem que ser responsável.

Independentemente da natureza do DP (descrição definida ou nome próprio), está disponível em (17) - além da interpretação ought-to-do análoga à de (14a) e (15a) - uma interpretação em que a obrigação (de morar em São Paulo) não recai sobre o sujeito (o jornalista ou João), mas sobre o ouvinte. Trata-se aí, como observa Hacquard (2006), de uma interpretação performativa do modal, característica do deôntico ought-to-be. ${ }^{10}$ Podemos imaginar um contexto em que o chefe de uma empresa ordena a um outro funcionário que o jornalista (ou João) seja transferido para São Paulo. A ordem é dada ao ouvinte, e não ao jornalista (ou ao João), que ocupa a posição de sujeito. O mesmo ocorre em (18), correlato ao exemplo (16a), no qual temos uma descrição definida com uma leitura atributiva mais saliente. Não é, portanto, o caso que a ocorrência de um participante agentivo no evento descrito pelo VP imponha ao deôntico uma interpretação ought-to-do. Há casos, como as interpretações sugeridas aqui para (17) e (18), em que, a despeito de um participante agentivo em posição baixa, a orientação do modal recai sobre o addressee, configurando uma leitura ought-to-be.

Apesar da invariável ocorrência de um participante agentivo na situação de fala, diferentemente do que poderíamos supor, a interpretação ought-to-be não está sempre disponível para o deôntico. Notamos que esta interpretação sofre, igualmente, restrições, que podem ser de natureza semântica, ou até mesmo pragmática. Em particular, quando o modal forma sequência com estados não passíveis de controle, a interpretação ought-to-be só será licenciada se o DP receber leitura atributiva, como ocorre em (19) - exemplo análogo ao (16b). Se tivermos um DP interpretado referencialmente - como é o caso do nome próprio Heitor em (20) -, a interpretação ought-to-be não será possível:

(19) A protagonista da próxima série pode ter estatura baixa.

(20) Heitor pode ter estatura baixa.

10 Esse tipo de deôntico aparece também, caracteristicamente, em contextos de roteiros cinematográficos e em instruções para peças de teatro. Pode-se imaginar que, em um roteiro, esteja escrito algo como "O homem de chapéu marrom deve se aproximar da câmera". Em casos como esses, é comum que o argumento do predicado sobre o qual o deôntico incide não seja sequer animado, como em "A pedra deve cair no início do segundo ato". 
Em (19), temos a possível realização de um ato de fala performativo, em que o falante dá ao ouvinte a permissão para escolher, dentre algumas pretendentes à protagonista da série, uma candidata que tenha estatura baixa. Neste caso, o DP sujeito não apresenta leitura referencial: a protagonista da próxima série - seja lá quem for - pode ter estatura baixa. Já em (20) - como a presença do nome próprio força uma relação referencial direta, sem mediação "descritiva" (cf.: KRIPKE 1980), temos apenas a possibilidade de interpretar o modal pode como um epistêmico. Conforme já argumentamos, a interpretação ought-to-do não ocorre com estados não passíveis de controle (dada a ausência do traço $[+\mathrm{Ag}]$ na eventualidade descrita pelo VP); logo, exemplos como (20) - estados não passíveis de controle com argumentos referenciais - não aceitam nenhum tipo de interpretação deôntica. ${ }^{11}$

Notamos, portanto, que há outra restrição - além da referente ao traço [+Ag] - associada aos deônticos, a qual tem relação com a interpretação do DP como referencial ou atributivo. Esta última, entretanto, se aplica apenas à interpretação do tipo ought-to-be em construções com estados não passíveis de controle: o deôntico alto só ocorre com esses estados se o DP a quem a propriedade não monitorável é atribuída não for referencial. Logo, essa restrição está relacionada também às propriedades do predicado sob o escopo do modal. O que podemos afirmar, neste momento, é que nem o addressee, que necessariamente porta o traço $[+\mathrm{Ag}]$, nem um participante agentivo no evento descrito pelo VP têm como controlar propriedades não monitoráveis, como a descrita pelo estativo ter estatura baixa. Por isso, não é possível dar uma ordem ou permissão para a manifestação de um estado (ou propriedade) desse tipo em um indivíduo já conhecido - no caso (20), de Heitor. O que torna exemplos com DPs atributivos (como (19)) aceitáveis é que, nesses casos, o addressee pode atuar na escolha de um referente que satisfaça essa propriedade. O DP atributivo deixa aberta essa possibilidade de seleção, ao contrário do que ocorre com o DP referencial, que obriga o addressee a agir diretamente sobre a propriedade. Se a propriedade em questão não for passível de monitoramento (como em (20)), essa exigência produz uma contradição. Daí que a única leitura disponível para o modal nessa sentença seja epistêmica.

Concluímos que, embora os deônticos ought-to-be possam formar sequência com estados não passíveis de controle, as condições em que essa configuração ocorre dependem da natureza atributiva do DP. Esse é precisamente o único caso em que temos estativos não passíveis de controle sob o escopo de um deôntico. Nesse caso, o deôntico checa o traço $[+\mathrm{Ag}]$ com o addressee; essa checagem ocorre, portanto, em posição alta.

${ }^{11}$ Essa diferença em relação ao comportamento dos DPs - referenciais e atributivos - com deônticos ought-to-be pode ser relevante para alguns debates antigos na filosofia da linguagem. O que esses nossos exemplos parecem insinuar é que as descrições definidas admitem tanto a leitura referencial quanto a leitura quantificacional (cf.: DONNELLAN 1966), e os nomes próprios só aceitam a leitura referencial (cf.: KRIPKE 1980) - daí eles resultarem sempre anômalos com estados não passíveis de controle sob o escopo de deônticos. 


\section{CONSIDERAÇÕES FINAIS}

Este estudo visa a contribuir para uma melhor compreensão sobre a interface sintaxe e semântica dos modais nas línguas naturais. Tentamos mostrar, a partir da análise de um fenômeno particular, que a interpretação dos modais é definida não somente por fatores semântico-pragmáticos (cf:: KRATZER 2012), tais quais a distinção entre usos referenciais e atributivos de DPs, mas também sintáticos. Na esteira da proposta de Hacquard (2006, 2010), vimos que há uma influência da semântica na medida em que os operadores deônticos demandam a presença de um agente na estrutura do evento sob seu escopo, mas também há uma influência da sintaxe, pois tais eventos só são acessíveis em posições previamente definidas na estrutura. Nossa pesquisa mostrou, também, que as propriedades da eventualidade descrita pelo VP restringem ou licenciam a interpretação deôntica em posição baixa. Vimos que os deônticos ought-to-do só co-ocorrem com estados controláveis - os quais, nesse sentido, se comportam de maneira semelhante a predicados de atividade -, e que os deônticos ought-to-be são mais tolerantes, embora apresentem uma restrição relativa ao modo como o DP é interpretado. O quadro abaixo apresenta uma síntese das principais relações e restrições depreendidas neste estudo:

\begin{tabular}{|c|c|c|}
\hline Tipos de Deônticos & Ougth-to-do & Ougth-to-be \\
\hline Predicado de Estado & & $\checkmark$ \\
\hline Estado controlável & $\checkmark$ & (apenas com DP atributivo) \\
\hline Estado não-controlável & $*$ & \\
\hline
\end{tabular}

Quadro 1: Sistematização das combinações de predicados estativos com os tipos de deônticos.

Ao examinarmos as intricadas relações que os deônticos estabelecem com os predicados estativos, cremos ter avançado na compreensão dessas duas classes. A depreensão das propriedades dos predicados sob o escopo do modal que influenciam na sua interpretação nos revela muito sobre a natureza dos modais e também dos predicados e eventualidades codificadas pelas línguas. Nossa conclusão, a respeito desse ponto, foi que nem os deônticos nem os estativos podem ser convenientemente caracterizados como classes homogêneas.

O comportamento diferenciado de tipos de estativos em relação aos deônticos reforça a tese básica segundo a qual as eventualidades não-dinâmicas se repartem entre aquelas que podem e as que não podem ser controladas. Essa divisão básica interna à classe dos estativos possibilitou rastrear algumas diferenças entre os deônticos do tipo ought-to-do e ought-to-be. Aqueles funcionam apenas com predicados estativos controláveis (em que um participante agentivo atua nas fases preparatórias da eventualidade descrita no VP), e estes funcionam com todos os tipos de estativos, embora apresentem restrição de outra natureza - relativa ao tipo de leitura assumida pelo DP (referencial ou atributiva). Essas evidências fornecem um respaldo adicional à hipótese aventada em Rech e Giachin (2014) e Pires de Oliveira e Rech (2016), segundo a qual a definição da modalidade está atrelada às propriedades do predicado sob o escopo do modal. 


\section{REFERÊNCIAS}

BACH, Emmon. 1981. On Time, Tense, and Aspect: An Essay in English Metaphysics. In COLE, Peter (Ed.), Radical Pragmatic. Academic Press: New York.

BASSO, Renato \& ILARI, Rodolfo. 2004. Estativos e suas características. Revista brasileira de linguística aplicada, v. 4, n. 1: pp. 15-26.

BERTINETTO, Pier Marco. 1991. Il Sintagma Verbale. In: RENZI, Lorenzo \& SALVI, Giampaolo (Eds.). Grande grammatica italiana di consultazione. Bologna: Il Mulino: pp. 13-161.

BRANDÃO, Ana Paula. 2014. A reference grammar of Paresi-Haliti (Arawak). Thesis, University of Texas at Austin.

BRENNAN, Virginia Mary. 1993. Root and Epistemic modal auxiliary verbs. 455fls. Ph.D. Thesis, University of Massachusetts Amherst.

CINQUE, Guglielmo. 2006. Restructuring and functional heads: the cartography of syntactic structures. New York: Editora Oxford University Press.

CINQUE, Guglielmo. 1999. Adverbs and Functional Heads: a cross-linguistic perspective. New York: Editora Oxford University Press.

DONNELLAN, Keith. 1966. Reference and definite descriptions. The philosophical review, v. 75, n. 3: pp. 281-304.

DONOHUE, Mark \& WICHMANN, Soren (eds.). 2008. The Typology of Semantic Alignment. Oxford: Oxford University Press.

DOWTY, David. 1979. Word Meaning and Montague Grammar. Dordretch: Reidel.

FELDMAN, Fred. 1986. Doing the Best We Can. Philosophical Studies Series in Philosophy 35. Dordrecht: Reidel.

HACQUARD, Valentine. 2010. On the Event Relativity of Modal Auxiliaries. Natural Language Semantics, 18(1): pp. 79-114.

HACQUARD, Valentine. 2006. Aspects of modality. 214fls. Tese de Doutorado. Massaschusetts Institute of Technology, Cambridge.

KENNY, Anthony. 1963. Action, Emotion and Will. London: Routledge.

KRATZER, Angelika. 2012. Modals and Conditionals. New York: Oxford University Press.

KRATZER, Angelika. 2001. Modality. In: STECHOW, A. von; WUNDERLICH, D. (Eds.). Semantik: Ein internationales Handbuch zeitgenössischer Forshhung. Berlin: mouton de Gruyter: pp. 639-650.

KRATZER, Angelika. 1981. The notional category of modality. In: EIKMEYER, H-J.; RIESER, H. Word, worlds, and contexts: new approaches to word semantics. Berlin: W. de Gruyter: pp. 38-74.

KRIPKE, Saul. 1980. Naming and Necessity. Cambridge: Harvard University Press.

PARSONS, Terence. 1990. Events in the Semantics of English. Cambridge: MIT Press.

PARTEE, Barbara. 1977. John is easy to please: In ZAMPOLLI, A. (Ed.). Linguistic structures processing. Amsterdam: North Holland. 
PESSOTTO DOS SANTOS, Ana Lúcia. 2015. Força e evidência: uma análise teórico experimental da semântica de 'pode', 'deve'e 'ter que'. 277f. Tese (Doutorado) - Curso de Linguística, Pós-graduação em Linguística, Universidade Federal de Santa Catarina, Florianópolis.

PIRES DE OLIVEIRA, Roberta \& RECH, Núbia S. Ferreira. Flavors of obligation: the syntax/ semantics of deontic deve in Brazilian Portuguese. Letras de Hoje, Porto Alegre, v. 51, n. 3: pp. 349-357, jul.-set. 2016.

RECANATI, François. 2010. Truth-conditional Pragmatics. New York: Oxford University Press.

RECH, Núbia S. Ferreira \& GIACHIN, Amanda. 2014. As interpretações disponíveis para os modais pode e deve em construcoes com predicados adjetivais. In: PIRES DE OLIVEIRA, Roberta (Org.) Revista Virtual de Estudos da Linguagem. Vol. 12, n. 8, novembro de 2014. Disponível em: $<$ http://www.revel.inf.br/pt/edicoes/?id=35>.

ROTHSTEIN, Susan. 2004. Structuring Events: A Study in the Semantics of Lexical Aspect. Blackwell Publishing, Oxford.

SEARLE, John R. 1958. Proper Names. Mind, v. 67, n. 266: pp. 166-173.

SPERBER, Dan \& WILSON, Deirdre. 2012. Meaning and Relevance. New York: Cambridge University Press.

VENDLER, Zeno. 1967. Linguistics in philosophy. New York: Cornell University Press.

YANG, Heisoon. 1997. Agentivity and nonstativity in English. Linguistic research, v. 33, n. 4: pp. 671-685. 